\title{
Dynamic methods for solid electrolyte sensors
}

\author{
A. Ruchets ${ }^{1}$, N. Donker ${ }^{2}$, D. Schönauer-Kamin'2, R. Moos², J. Zosel1', M. Mertig ${ }^{1}$ \\ ${ }^{1}$ Kurt-Schwabe-Institut für Mess- und Sensortechnik e. V. Meinsberg, Kurt-Schwabe-Straße 4, \\ 04736 Waldheim, Germany \\ 2 Department of Functional Materials, University of Bayreuth, \\ 95440 Bayreuth, Germany \\ A. Ruchets (ruchets@ksi-meinsberg.de)
}

\begin{abstract}
:
First investigations revealed that solid electrolyte sensors based on yttria-stabilized zirconia can exhibit improved selectivity to redox active gases when they are operated with dynamic electrochemical methods like cyclic voltammetry or pulsed polarization. To clarify basic electrochemical processes at the gas electrode, extensive investigations in non-equilibrated gas mixtures containing hydrogen, carbon monoxide and propene have been carried out by using cyclic polarization methods. The results show that it is possible to distinguish between different species in a mixture by using sensors which are non-selective when operated with static electrochemical methods.
\end{abstract}

Key words: yttria-stabilized zirconia (YSZ), cyclic voltammetry, pulsed polarization, dynamic methods.

\section{Introduction}

Concentration measurements of redox-active gases in non-equilibrated mixtures are required in different sensor applications. These applications include exhaust gas emission monitoring and on-board combustion control, fuel gas (hydrogen and hydrocarbons) measurement for explosion hazard detection, observation of carbon monoxide and nitrogen oxides in air pollution monitoring as well as measurements in medical and biotechnological processes.

Till now most solid electrolyte gas sensors (SES) based on yttria stabilized zirconia (YSZ) are used for gas concentration measurements with stationary potentiometric, amperometric, or coulometric methods [1]. Dynamic methods like impedance spectroscopy [2], pulsed polarization [3] and cyclic polarization [4] are investigated increasingly but are not applied in practice in a broader range.

One the one hand, it was demonstrated already that these dynamic methods can provide selective measurements of single components in non-equilibrated mixtures with SES. On the other hand, the mechanisms and kinetics of electrochemical processes at hot and catalytically highly active gas electrodes that allow selective gas detection are still not fully understood and should be clarified.
Therefore, the work presented in this contribution is directed toward the detailed investigation of the dynamic response of $\mathrm{Pt}$ electrodes on YSZ in non-equilibrated gas mixtures in a broad range of gases, their concentrations, temperature and electrochemical parameters.

\section{Experimental}

For simultaneous control and regulation of oxygen and test-gas concentrations, the setup shown in Fig. 1 was designed and tested.

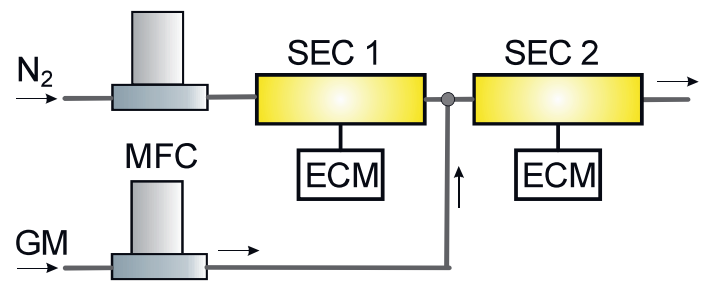

Fig. 1. Experimental setup. MFC - mass flow controllers, SEC - solid electrolyte cell, GM - diluted gas mixture with $\mathrm{H}_{2}, \mathrm{CO}$, or $\mathrm{C}_{3} \mathrm{H}_{6}$, ECM - electrochemical measuring system and temperature control

Mixtures of $\mathrm{N}_{2}$ (quality 5.0 ) and a diluted test gas containing $\mathrm{H}_{2}, \mathrm{CO}$, or $\mathrm{C}_{3} \mathrm{H}_{6}$, were established by mass flow controllers (Brooks Instruments, Hatfield, USA). The total flow rate was $10 \mathrm{ml} / \mathrm{min}$. The solid electrolyte cells 1 and 2 (SEC 1, SEC 2) shown in Fig. 1 were purchased from Zirox Sensoren and Elektronik $\mathrm{GmbH}$, Greifswald, Germany $\left(\mathrm{O}_{2}-\mathrm{DF}-28.0\right)$. 
The construction of these cells is described in detail elsewhere [5]. It was modified for these experiments to ensure leakage rates below $10^{-9} \mathrm{mbar} \cdot \mathrm{L} / \mathrm{s}$. The area of the measuring electrode amounts to $5 \mathrm{~cm}^{2}$.

For adjusting different constant oxygen concentrations in the mixture, SEC 1 was constantly polarized. Adding the test gas between both SEC ensures that predefined mixtures of nitrogen, oxygen, and the applied oxidizable gases are measured by CV in SEC 2. Cyclic voltammograms were taken with a measurement system Reference $600^{\mathrm{TM}}$ and Interface 1000 (Gamry Instruments, Warminster, USA). Since during the first cycle of all voltammograms the electrode is conditioned after different prehistories, the second cycle was evaluated in each experiment to improve reproducibility.

\section{Results}

For testing the setup given in Fig. 1, the correct dosage of different hydrogen concentrations at constant oxygen partial pressure was evaluated by a coulometric measurement at SEC 2 .

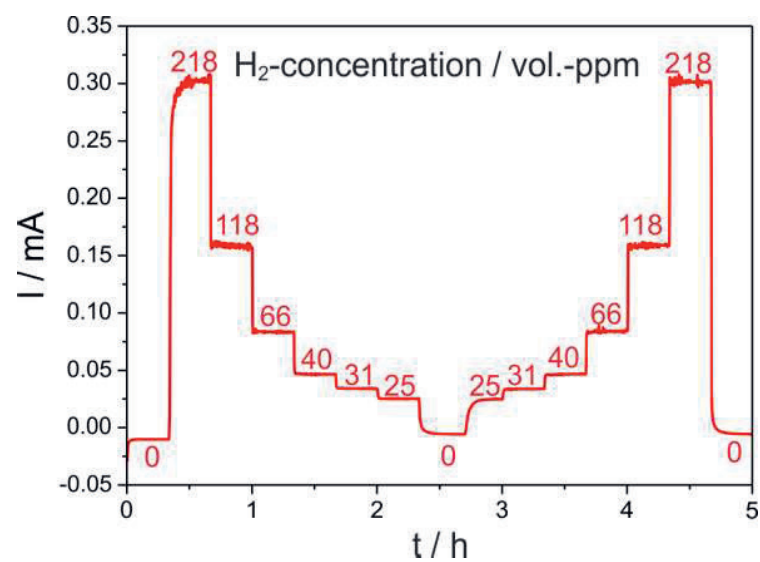

Fig. 2. Current in coulometric measurements for different $\mathrm{H}_{2}$-concentrations, gas flow: $10 \mathrm{ml} / \mathrm{min}$, SECs temperatures: $750^{\circ} \mathrm{C}$, potential of SEC 1: $-270 m V$, potential of SEC 2: $-450 m V$ (vs. Pt/air ref.).

The results in Fig. 2 prove that the expected Faradaic currents were measured long-term stable and with appropriate reproducibility. As an example of the multi-gas measurements, in Fig. 3, the CV curves of a hydrogen containing mixture are provided. They indicate a hydrogen related peak within the potential range between -0.4 and $-0.2 \mathrm{~V}$ at anodic polarization direction. With increasing hydrogen concentrations up to $\varphi\left(\mathrm{H}_{2}\right)=100$ vol.-ppm the peak is shifted to more positive potentials. Peak height and area are increasing with rising $\mathrm{H}_{2}$-concentration up to about 50 vol.-ppm. At $\mathrm{H}_{2}$-concentrations above 100 vol.-ppm, a saturation effect causes decreasing peak height and area. This tendency was also found at higher oxygen concentrations of up to 17 vol.-ppm [5].

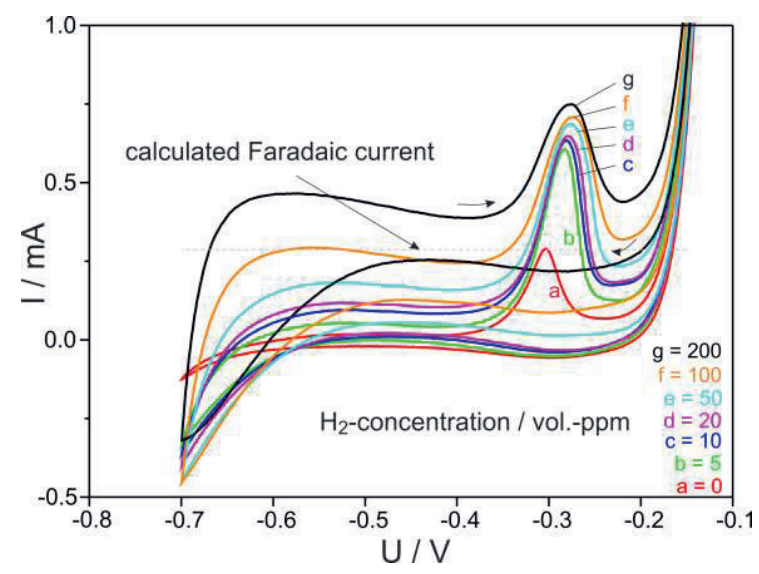

Fig. 3. Cyclic voltammograms for different $\mathrm{H}_{2}$ concentrations, gas flow: $10 \mathrm{ml} / \mathrm{min}$, SECs temperatures: $750^{\circ} \mathrm{C}$, potential of SEC 1: $-305 \mathrm{mV}$, potential sweep rate: $10 \mathrm{mV} / \mathrm{s}, \varphi\left(\mathrm{O}_{2}\right): 0.2 \mathrm{vol}$. $-\mathrm{ppm}$.

\section{Conclusion}

For the example of hydrogen, it was shown that it is possible to distinguish between redox active gas components in gas mixtures by using sensors based on YSZ which are operated by means of cyclic voltammetry. In consequence, it is demonstrated that dynamic voltammetric polarization can be a way to improve selectivity also at YSZ-based gas sensors.

\section{Acknowledgement}

The work is funded by the German Research Foundation (DFG) under project "Dynamische Methoden für elektrochemische Gassensoren (DynaSens)" (MO 1060/30-1, ZO 139/3-1).

\section{References}

[1] S. Zhuiykov, Electrochemistry of Zirconia Gas Sensors. CRC Press, Boca Raton (2007); ISBN 978-1-4200-4762-2

[2] K. Schindler, D. Schmeisser, U. Vohrer, H.D. Wiemhöfer, W. Göpel, Spectroscopic and electrical studies of yttria-stabilized zirconia for oxygen sensors, Sensors and Actuators $B$ Chemical 17, 555-568 (1989); doi: 10.1016/0250-6874(89)80045-9

[3] S. Fischer, R. Pohle, M. Fleischer, R. Moos, Method for reliable detection of different exhaust gas components by pulsed discharge measurements using standard zirconia based sensors, Procedia Chemistry 1, 585-588 (2009); doi: 10.1016/j.proche.2009.07.146

[4] G. Henze, Polarographie und Voltammetrie: Grundlagen und analytische Praxis, Chapter: Methoden, Springer, Berlin, 22-65 (2001); ISBN 978-3-642-56492-5

[5] M. Schelter J. Zosel, W. Oelßner, U. Guth, M. Mertig, Electrolyte sensor for the analysis of gaseous mixtures J. Sens. Sens. Syst. 5, 319324 (2016); doi: 10.5194/jsss-5-319-2016 